period was statistically insignificant. But FLACC score at $30 \mathrm{~min}$ in post-operative period was significant for Group C (mean $-5.2 \pm 1.6, \mathrm{p}-0.035)$ in comparison to Group A $(7.2 \pm 1.9)$ and Group B $(6.3 \pm 1.2)$. FLACC score for 24 hours, remained less for Group $\mathrm{C}$, it was statistically insignificant but could be clinically significant.

Even parental satisfaction score was statistically significant for Group C ( $p=0.016)$.

Conclusions No dose of rescue analgesia was required in Group C (Group A - 2/10, Group B - 1/10). It was statistically insignificant but could be clinically significant. Hence USG guided posterior QLB has much better post - operative analgesic effect, without any complications.

IEC clearance was obtained with a letter reference number: AIIMS/Pat/IEC/PGTh/Jan19/15.

\section{CLINICIAN-LED SURVEY ON ESSENTIAL DOCUMENTATION FOR REGIONAL ANAESTHESIA VS CURRENT DOCUMENTATION STANDARDS}

${ }^{1} \mathrm{E}$ Pack*, ${ }^{2} \mathrm{~S}$ Shanmuganathan. ${ }^{1}$ Great Ormond Street Hospital, London, UK; ${ }^{2}$ Royal National Orthopaedic Hospital, Stanmore, UK

\subsection{6/rapm-2021-ESRA.139}

Background and Aims No standards exist for documentation of peripheral nerve blocks (PNBs). Aim: To identify what clinicians think should be essential documentation and evaluate whether current practice meets these standards.

Methods Anaesthetists from three hospitals were surveyed. Forty suggested documentation topics were listed. We asked what they thought should be essential documentation and what they were currently documenting.

We performed a retrospective audit across two hospitals, looking at which of the forty topics had been documented for all PNBs. In the hospital using handwritten notes, anaesthetic charts were audited over two-weeks, and in the hospital using a computerised programme, notes were audited over 15months.

Results 41 anaesthetists were surveyed. 12 documentation topics were thought to be essential by over $80 \%$. Documentation of 38 PNBs were audited in the hospital using handwritten notes, and 960 PNBs in the hospital using computerised records.
Conclusions We found a discrepancy between perceived and actual documentation. Computerised systems improve this but are reliant on programming, demonstrated as only one percent of notes documented complications because no text field prompted this. Clear guidelines are required so that documentation of PNBs can be standardised.

\section{DURATION OF BLOCKADE OF PERIPHERAL NERVES WITH LOW CONCENTRATED BUPIVACAINE SOLUTION DEPENDING OF THE ADJUVANTS}

M Barsa*. Danylo Halytsky Lviv National Medical University, Lviv, Ukraine

\subsection{6/rapm-2021-ESRA. 140}

Background and Aims Anesthesiology is showin a tendency to reduce use of opioids. This is due to respiratory depression and hypoxia in postoperative period. In addition - opioids does not allow patient to mobilize in early postoperative period, which increases the risk of thromboembolic complications. Rapid progress in development of regional methods of analgesia has significantly reduced the use of opioids and has provided sufficient pain relief. Despite the results achieved, we continue to search for perfect combination of local anesthetic and adjuvants to ensure long-lasting and safe analgesia.

Methods Seventy peripheral nerve blocks were performed in patients undergoing orthopedic surgery. Patients were randomly assigned to 2 groups (G1, G2), depending on the adjuvant: G1 - blockade with solution of bupivacaine $0,375 \%$ and dexamethasone $0,02 \%$; Gr2 - blockade with a solution of bupivacaine $0,375 \%$ with dexamethasone $0,02 \%$ and

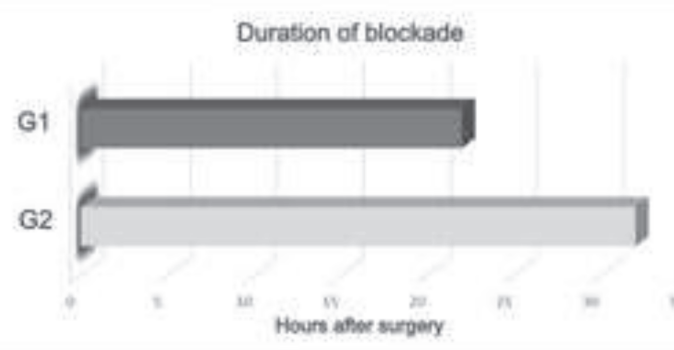

Abstract 140 Figure 1

Abstract 139 Table 112 essential topics and their documentation

\begin{tabular}{|c|c|c|c|}
\hline & & Handwritten & Computerised \\
\hline Topic & $\begin{array}{l}\text { \% who think they } \\
\text { document this }\end{array}$ & \multicolumn{2}{|c|}{ \% of notes this was documented } \\
\hline Stop before you block & E9:6 & $39 \%$ & $76 \%$ \\
\hline Performing doctor & $84 \%$ & 2635 & $76 \%$ \\
\hline Which PNB performed & $100 \%$ & $95 \%$ & $98 \%$ \\
\hline Drug/dose of sedation & $89 \%$ & $100 \%$ & not collected \\
\hline Patient awake, sedated or asleep & $95 \%$ & 925 & $94 \% 5$ \\
\hline Aseptic technique & $97 \%$ & $45 \%$ & $90 \%$ \\
\hline Ultrasound or landmark & $93 \%$ & $92 \%$ & $78 \%$ \\
\hline Needle type & $89 \%$ & 8936 & $79 \%$ \\
\hline Needle size & $89 \%$ & $95 \%$ & $88 \%$ \\
\hline Drug/concentration of local anaesthetic & $97 \%$ & $95 \%$ & $48 \%$ \\
\hline Pain/paraesthesia on injection & 719 & $45 \%$ & 8546 \\
\hline Complications & $91 \%$ & $47 \%$ & 136 \\
\hline
\end{tabular}

